\title{
STERIC ASPECTS OF THE PHOTOCHEMISTRY OF CONJUGATED DIENES AND TRIENES
}

\author{
William G. Dauben, Michael S. Kellogg $\dagger$, Jeffrey I. Seeman $\dagger$, \\ Noel D. Vietmeyer and Peter H. WendschuH $\ddagger$
}

\begin{abstract}
Department of Chemistry, University of California, Berkeley, California 94720, USA
\end{abstract}

\begin{abstract}
The photochemical transformation of the 1,3-cyclohexadiene chromophore can lead via orbital symmetry allowed pathways either to a bicyclo[2.2.0]hex-2-ene derivative or to a 1,3,5-hexatriene derivative. It was established that the ground state conformation of the starting 1,3-cyclohexadiene controls the primary photochemical reaction. The photoproducts composition can be changed by variation of the wavelength or of the temperature. The mechanisms of these processes are discussed. The photochemical transformation of a 1,3,5-hexatriene derivative to a bicyclo[3.1.0]hex-2-ene has been shown to proceed from an $s$-trans,s-cis conformation. The mechanism of the rearrangement has been shown to be an extension of the rearrangement of a 1,3-butadiene to a bicyclo[1.1.0]butane.
\end{abstract}

In the study of the photochemistry of 1,3-cyclohexadienes, the evaluation of the photoequilibrium between the diene and the resultant triene is important<smiles>[R]C1CCC2C3=CC=C4CC(O)CCC4C3CCC12</smiles><smiles>[R]C1CCC2C(/C=C\C3=CCCC(O)C3)=CCCC12</smiles><smiles>O=S1(=O)CCSCCO1</smiles>

1<smiles>[R]C1CCC2C(/C=C/C3=C(C)CCC(O)C3)=CCCC12C</smiles><smiles>C#CC(C)C(=C)/C=C1/CC[C@H](C(C)(C)C)[C@H]2CCC[C@]1(C(=O)O)C2=C</smiles>

$\dagger$ National Institute of Health Predoctoral Fellow.

$\ddagger$ National Science Foundation Predoctoral Fellow. 
since it permits one to gain some information as to what routes are available for energy consumption. For example, in the study of the photochemistry to pre-vitamin D (1) it is known that the ring-opening reaction is twenty times more efficient that the ring closure process, thus making other transformations of the triene competitive photoreactions ${ }^{1}$. In the case of palustric acid (2), however, the opening and closing processes are about of equal efficiencies and these two routes can utilize most of the energy, making other processes of minor concern ${ }^{2}$. This enhanced $\operatorname{rin}_{\xi}$ closure efficiency has been explained on conformational grounds ${ }^{2}$. Rotation of the terminal double bond to the s-trans conformation $\mathbf{4}$ is energetically unfavourable since the isopropyl group sterically interacts with the exocyclic methylene group; thus, the $s$-cis conformation 3 with the correct geometry for efficient photo-induced ring closure is present in high concentration. In the vitamin D case, the presence of a tetrasubstituted terminal double bond minimizes the energy difference between the two rotamers and the strain is relieved by the cis-trans isomerization of the central double bond.

This substitution effect has been further evaluated by a study of the photochemistry of 3-alkyl-6,6,9,9-tetramethyl- $\Delta^{3,5(10)}$-hexalins $(5)^{3}$. These structures are analogous to palustric acid and serve as a good probe for the

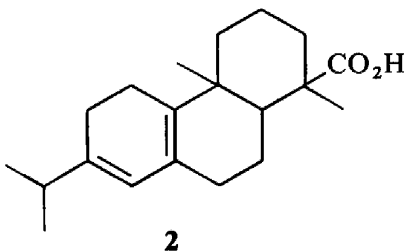

2

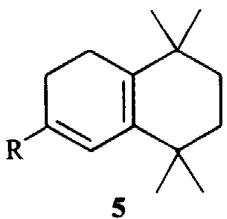

$\mathrm{R}=\mathrm{H}, \mathrm{Me}, i-\mathrm{Pr}, t-\mathrm{Bu}$

postulated conformational effect. The composite photochemistry of this series of dienes can be summarized by the set of equations shown in Chart $I$. There was first formed the triene 6 by the ring-opening reaction, followed by the buildup of the two final photoproducts, the bicyclo[3.1.0]hex-2-ene 7 and the cyclobutene 8 . Two important results are to be noted in the comparison

Chart I

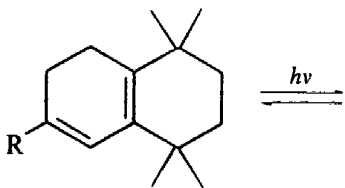

5

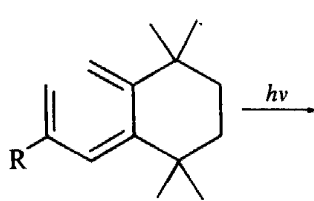

6<smiles>[R]C(=C)C1CC2=C(C1C)C(C)(C)CCC2(C)C</smiles>

7
8

\begin{tabular}{lrr}
\multicolumn{1}{c}{$\mathrm{R}$} & $t_{\frac{1}{2}}, \mathrm{~h}$ & $\mathbf{7 / 8}$ \\
$\mathrm{H}$ & 0.4 & 2.3 \\
$\mathrm{Me}$ & 2.1 & 1.0 \\
$i \cdot \mathrm{Pr}$ & 8.5 & 0.3 \\
$t-\mathrm{Bu}$ & 43.5 & 0.2
\end{tabular}


of the results obtained. First, the rate of disappearance of the starting material dropped as the steric bulk of the substituent increased. Secondly, as the rate of disappearance became slower, the ratio of the products of the reaction changed, i.e. the ratio of the bicyclohexene 7 to the cyclobutene 8 decreased.

The cyclization of a 1,3,5-hexatriene to a 1,3-cyclohexadiene is limited to a triene with an s-cis conformation $\mathbf{6}$. Consideration of the conformational

\section{Chart II}<smiles>[R]C1=CC2=C(CC1)C(C)(C)CCC2(C)C</smiles>

5

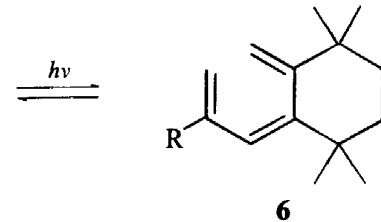

6

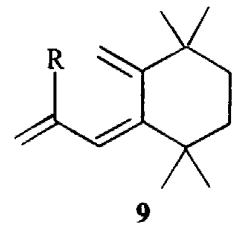

9
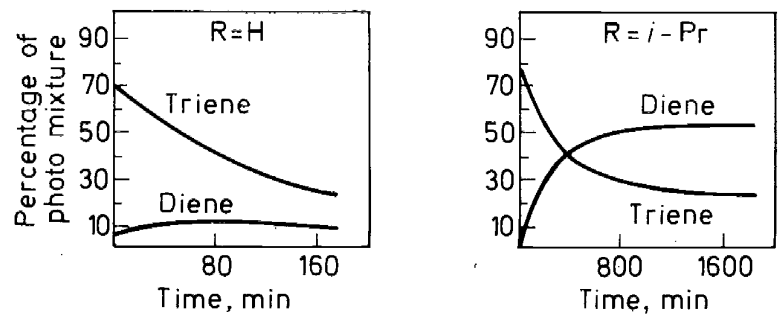

equilibrium of the triene clearly showed that as the steric bulk of the alkyl group on the triene increased, the concentration of the s-cis conformation should increase relative to the concentration of the s-trans rotamer 9. With such a change in concentration of the two major conformations and with the reasonable assumption that the spectra of all the $s$-cis and all the $s$-trans conformations are similar*, it can be expected that the efficiency of the photo-induced reclosure of triene to diene should increase as the substituent becomes larger. The overall result of this substitutent effect would be to decrease the rate of disappearance of the diene.

The foregoing concept requires that when the triene, itself, is irradiated, as the steric bulk of the substituent increases the amount of cyclic diene formed should be greater. It has been found as shown on Chart $I I$, that when $\mathbf{R}=\mathbf{H}$, the most efficient process is the formation of overirradiation products, whereas, when $\mathbf{R}=i \operatorname{Pr}$ the major reaction is the formation of the cyclic diene $^{3}$. These results are directly attributable to the steric effect in the triene and are not due to other factors, such as enhanced efficiency of internal conversion in the diene manifold since it has been found that quantum yields for the formation of trienes from the 1,3-cyclohexadienes in this series are the same. Thus, by changing the steric bulk of a peripheral substituent it is

* The Curtin-Hammett principle does not apply with regard to the photoexcitation of conformers with different absorption spectra. 
possible to effect changes in the conformational equilibrium of the triene and by controlling the concentration of the $s$-cis conformation it is possible to change the photochemical stability of a 1,3-cyclohexadiene.

This steric effect of the alkyl substituent on the conformation of the triene also was reflected in the course of the final irreversible photoreactions it underwent. It was found that as the steric bulk of the substituent increased the amount of cyclobutene-type product 8 formed increased and the amount of<smiles>[R]C(=C)/C=C1\C(=C)C(C)(C)CCC1(C)C</smiles>

9

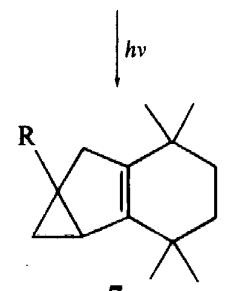

7

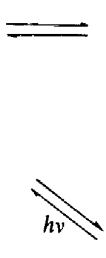<smiles>[R]C(=C)/C=C1\C(=C)C(C)(C)CCC1(C)C</smiles>

6<smiles>C1C[C@H]2CC12</smiles><smiles>[R]C(=C)C1CC2=C(C1C)C(C)(C)CCC2(C)C</smiles>

bicyclo[3.1.0]hexene-type 7 product decreased. Since this diminution of yield of the bicyclohexene paralleled the lowering of the concentration of the $s$-trans conformation, it was indicative that a requirement for the formation of such a bicyclic structure is for the triene to possess an s-trans, s-cis conformation.

Prior to this study of simple model compounds there were indications that such a conformation was, indeed, involved in this type of cyclization. The first example reported for the formation of the bicyclo[3.1.0]hex-2-ene structure from an acyclic conjugated triene was the transformation of vitamin $\mathrm{D}_{2}$ (10) to suprasterol I (11) ${ }^{4}$ and suprasterol II (12) ${ }^{5}$. It is known from $x$-ray studies that the most stable conformation of the vitamin is in the extended

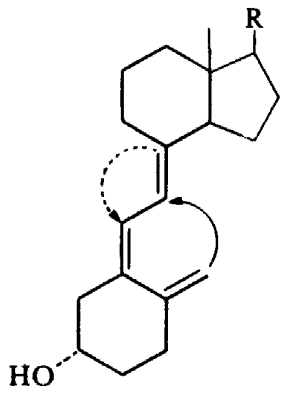

10

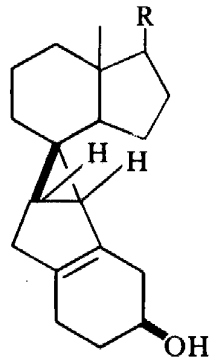

11 
<smiles>[R]C1CCC2C34CCCC3=C3CC(O)CCC3=CCCC4=CCCC12C</smiles>

10

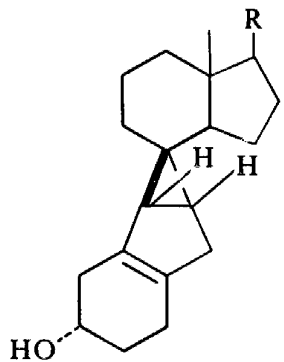

12

form, equivalent to s-trans, s-cis. Ring closure in an identical manner to the model cases would yield the overirradiation products suprasterols I and II. The stereochemical differences in these two compounds arise only from the direction of the ring closure.

Since this photo-induced ring closure of a 1,3,5-hexatriene chromophore to a bicyclo[3.1.0] hex-2-ene system was first reported in $1958^{5}$ many acyclic trienes have been found to undergo this rearrangement ${ }^{6}$ but only one example of a cyclic triene (1,3,5-cyclooctatriene) has been reported ${ }^{7}$. The presence of a triene in a ring tends to restrict the conformational mobility of the triene system and thus such a system should permit a better evaluation of the conformational effects on the photochemical routes followed.

The general procedure followed in this present study was to prepare the desired triene by photo-induced valence isomerization of a 1,3-cyclohexadiene. In the case of trans,cis,cis-1,3,5-cyclononatriene (14), formed from cis-bicyclo[4.3.0]nona-2,4-diene $(13)^{8}$, continued irradiation at $254 \mathrm{~nm}$<smiles>C1=C[C@H]2CCC[C@H]2C=C1</smiles>

13

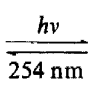<smiles>C1=CC=Cc2ccccc2C=C1</smiles>

14

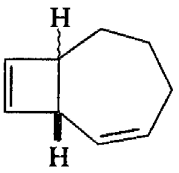

15a<smiles>C1=CC/C=C\CC/C=C\C1</smiles>

$15 b$

1,3-Suprafacial H-rearrangement

gave only two overirradiation products resulting from the triene. These compounds were bicyclo[5.2.0]nona-2,8-diene (15a) resulting from an electrocyclic reaction of a diene portion of the chromophore and 1,3,6-cyclononatriene (15b) resulting from a 1,3-suprafacial hydrogen sigmatropic rearrangement. No product with a bicyclo[3.1.0] hexene structure was formed.

The irradiation of cis-bicyclo[5.4.0] undeca-8,10-diene $(\mathbf{1 6})^{*}$ first set up a photoequilibrium between the diene and cycloundeca-1,3,5-triene (17).

* This diene was prepared from the adduct of tetrachlorocyclopentadienone ketal with cycloheptene, followed by dechlorination, hydrolysis of the ketal, and decarbonylation of the ketone. 
Continued irradiation yielded the bicyclo[2.2.0]hexene derivative $\mathbf{1 8}$ from the diene and the unique endo,exo-tricyclo[5.3.1.0 8,11$]$ undec-9-ene (19). The structure of this material was established by degradation and by spectral evaluation*. This bicyclo[3.1.0]hexene was thermally quite stable and at
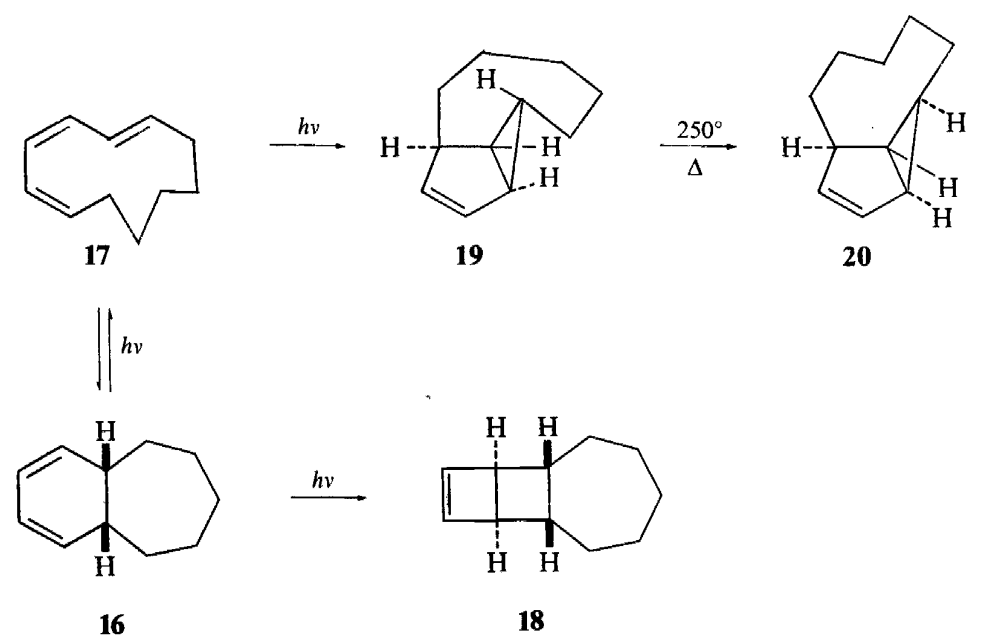

$250^{\circ}$ its halflife was 40 minutes; the pyrolysis product was shown to be the isomeric endo,endo-tricyclo [5.3.1.0.10.11] undec-8-ene (20).

Before the significance of this finding can be evaluated, the mechanistic details for the conversion of an acyclic 1,3,5-triene to a bicyclo[3.1.0] hex-2ene must be analysed. This transformation has been viewed as a photochemical Diels-Alder reaction and has been designated as a $\left[\pi_{\pi} 4+\pi^{2}\right]$ cycloaddition $^{9}$. As shown in Chart III, for the process to occur in the electronic excited state, the cycloaddition must be either $\left[{ }_{\pi} 4_{\mathrm{a}}+{ }_{\pi} 2_{\mathrm{s}}\right]$ or $\left[{ }_{\pi} 4_{\mathrm{s}}+\right.$ ${ }_{\pi} 2_{\mathrm{a}}$ ]. Excluding the formation of a trans-fused bicyclo[3.1.0]hex-2-ene, then with trans,cis,cis-cycloundeca-1,3,5-triene it is first to be noted that both the s-cis,s-cis and the s-trans,s-cis conformation yield the same two compounds but only in the $\left[{ }_{\pi} 4_{a}+{ }_{\pi} 2_{s}\right]$ process is a compound of reasonable steric strain possible. If the ring system be sufficiently large, then the so-called ' $A-E$ ' bond could be strainless in either isomer. Inherent in this theoretical treatment is the complete separation of orbital symmetry features of the full triene system, in this treatment the triene being divided into $\mathrm{a}_{\pi} 4$ and $\mathrm{a}{ }_{\pi} 2$ basis set, i.e. the symmetry of the lowest unoccupied molecular orbital (LUMO) of the triene is not considered. However, if there be some coupling of the two basis sets, secondary effects due to the orbital symmetry of the excited state (LUMO)

* Using the n.m.r. programme kindly supplied by Professor H. E. Zimmerman and employing experimental values for the chemical shifts and literature values for the coupling constants from related systems possessing the same geometry, ${ }^{6 h}$, the calculated spectrum was in excellent agreement with the experimental results. 


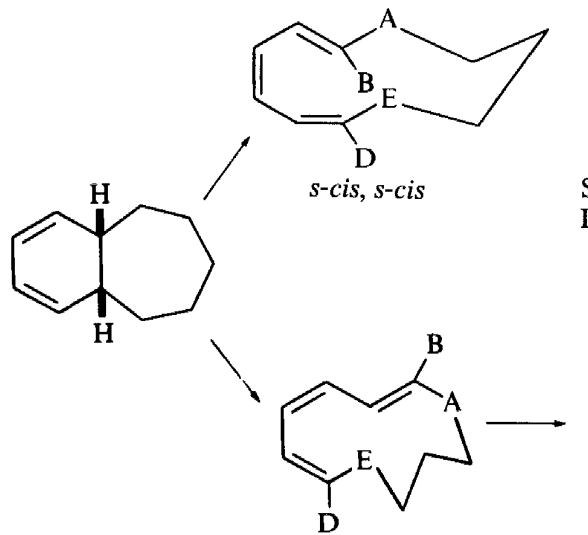

$\begin{array}{lc}\text { Steric } & \text { Probable } \\ \text { LUMO } & \text { Not allowed }\end{array}$

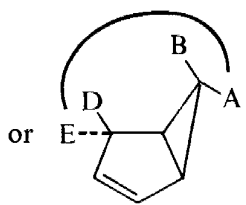

$\left[4_{\mathrm{s}}+{ }_{\pi}{ }^{2} \mathrm{a}\right]$

Improbable

Not allowed

Improbable Allowed

can favour one allowed process over the other. Considering the LUMO (nodal) symmetry, the $\left[4_{a} 4_{a}+{ }_{\pi} 2_{s}\right]$ process is only allowed from the $s$-cis,s-cis conformation and the $\left[{ }_{\pi} 4_{s}+{ }_{\pi} 2_{a}\right]$ process from the s-trans,s-cis conformation.

Using these theoretical conclusions, it follows that the trans,cis,ciscycloundeca-1,3,5-triene should yield either the endo,endo- or the exo,exoisomer. If the LUMO is considered along with the previously suggested preference for reaction from an s-trans,s-cis conformation only the exo,exoisomer should be formed. Regardless of the specific orbital symmetry features of the process, it is seen that the two isomers formed from a concerted $\left[\pi^{4}+\pi^{2}\right]$ process must differ in stereochemistry at two centres.

The actual product formed in the reaction studied was neither of the stereoisomers predicted but was the endo,exo isomer. To account for the product

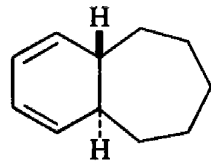

22<smiles>C1=C\C=C\CCCCC\C=C/1</smiles>
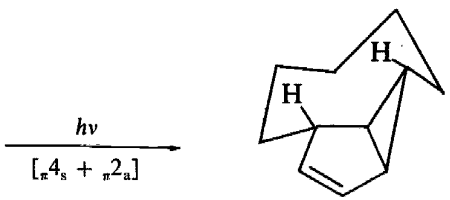

17<smiles>C1=C\C=C\CCCCC/C=C/1</smiles>

21

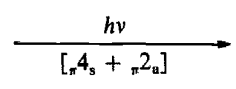

$\mathrm{H}$

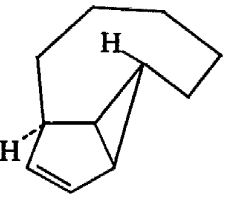

19 
within the limits of the postulated concerted process would require that the product be formed from the trans,cis,trans triene (21). The structure of the starting triene was established by its thermal conversion to trans-bicyclo[5.4.0] undeca-8,10-diene (22). The possibility did exist that there was an initial isomerization to the trans,cis,trans isomer and this compound, in turn, was the direct precursor of the endo,exo product. Such a possibility did not seem reasonable since in all previous cases, trans, cis,trans trienes are in photoequilibrium with the related 1,3-cyclohexadiene. To evaluate this possibility, however, the composition of the reaction mixture at various time intervals was obtained and it was found that the bicyclo[3.1.0]hexene product built up early in the reaction and before sufficient trans,cis,trans trienes could be formed to act as the precursor. Thus, in this case it must be concluded that the triene to bicyclo[3.1.0]hexene conversion does not occur via a concerted $\left[\pi+{ }_{\pi} 2\right]$ cycloaddition route. A similar conclusion has been recently arrived at by Seeley ${ }^{6 i}$ based upon an $\left[{ }_{\pi} 8+{ }_{\pi} 2\right]$ system.

To gain further insight into the possible role of strain in the control of the mechanistic path followed, cis-bicyclo[4.4.0]deca-2,4-diene (23)* was studied. It was found that on extended irradiation there was formed trans-bicyclo-

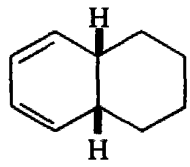

23

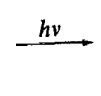

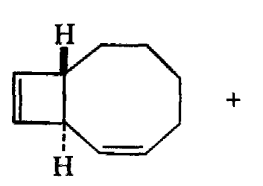

24

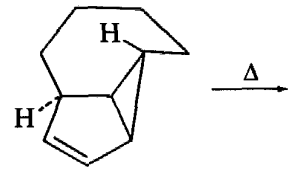

25

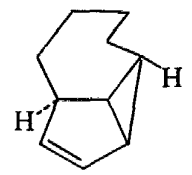

26

[6.2.0]deca-2,9-diene (24) and endo,exo-tricyclo[4.3.1.0.9.10]deca-7-ene (25). This latter material upon heating to $75^{\circ}$ underwent isomerization to endoendo isomer 26. This finding of the tricyclic product in yet a more strained system suggests that if, indeed, the mechanism of the photoisomerization process in the cyclic triene system might be different from that of the acyclic trienes, at least it is general for the cyclic series.

The formation of highly strained products is not unusual in photochemistry and close examination of such materials often leads to mechanistic understanding of the reaction process. In the present study, it was noted that the stereochemistry of the three-membered ring was that which would have resulted from a conrotatory process. Furthermore, examination of the stereochemistry of the cyclopropane ring in the three bicyclo[3.1.0] hexenes 30-32, prepared from the acyclic trienes $27-29$ respectively ${ }^{6 c, e, g}$, again showed a conrotatory route had been followed. The constancy of the stereochemical pathway followed indicated that most likely the ring closure to the cyclopropane ring was a concerted process, the stereochemistry of which follows the orbital symmetry requirements for the closure of an allylic system. This finding was reminiscent of our earlier results related to the conversion of a

* This material was prepared in a similar manner to that employed for 16 except cyclohexene was used. 
<smiles>[BH3-]</smiles>

17

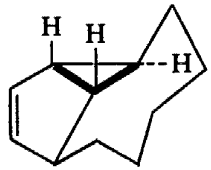

19<smiles>O=C1CCCCCCCCCCCC1</smiles>

23

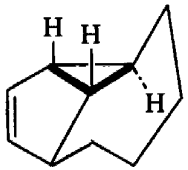

25

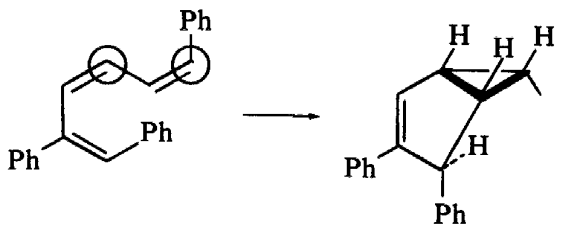

27<smiles>C(=C\c1ccccc1)\C=C\c1ccccc1</smiles>

28

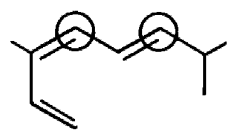

29
31

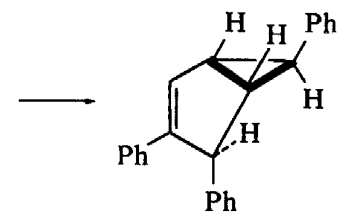

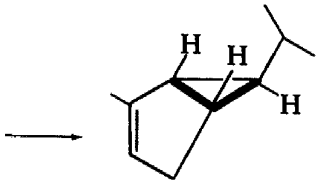

32

1,3-butadiene to a bicyclo[1.1.0]butane ${ }^{10}$. In this latter process, it was postulated that the reaction was initiated from the twisted, relaxed conformation of the excited state (Chart IV). It was shown that one cyclopropane ring was formed by a conrotatory ring closure; the orthogonal orbital not being part part of the three-atom basis set was free from orbital symmetry requirements and it formed a bond with the nearest orbital to complete the reaction.

\section{Chart IV}
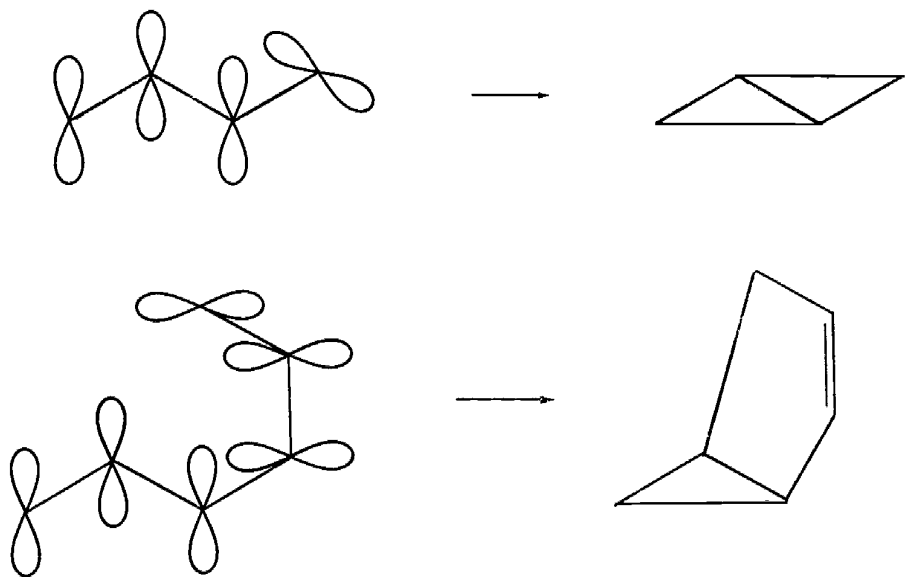
The bicyclo[3.1.0]hex-2-ene can be considered as a vinylogous bicyclobutane and the photoprocess leading to its formation can occur in a manner analogous to the bicyclobutane reaction. It is reasonable to assume ${ }^{11}$ that the electronically excited but vibrationally relaxed triene has a configuration where the central double bond has twisted, the resulting three-carbon units having an orthogonal arrangement. The reaction could then proceed by the allowed conrotatory closure to the cyclopropane ring followed by the closure of the five-membered ring.

This postulate has many interesting stereochemical features. First, it is to be noted that for the reaction to occur it is essential for the process to occur from an s-trans,s-cis conformation. As mentioned earlier, the involvement of such a conformation has been indicated. Furthermore, if other trienes are arranged in their most stable s-trans,s-cis conformation (see Chart $V$ ),

Chart $V$
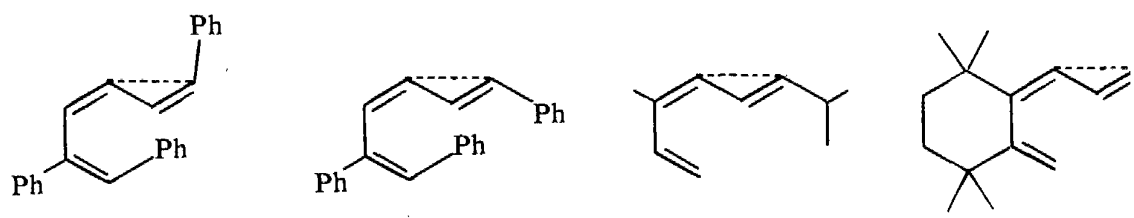<smiles>C=C(C(C(=C)c1ccccc1)=C(c1ccccc1)c1ccccc1)c1ccccc1</smiles><smiles>C=CC=c1ccccc1=C</smiles><smiles>[R]C1CCC2C(=CC=C3CC(O)CCC3=C)CCCC12C</smiles>

it is found that the cyclopropane ring closure always results from the atom: involved in the s-trans system. With these generalizations, it is possible to explain the high specificity found in the reaction of unsymmetrical trienes

Another stereochemical feature to be considered is the configuration of thi asymmetric centre resulting from the formation of the five-membered ring Of the four examples available for evaluation, i.e. cyclodeca-1,3,5-triene. cycloundeca-1,3,5-triene and the cis- and trans-6-phenyl-trans 1,2-diphenylhexa-1,3,5-trienes $\mathbf{2 7}$ and $\mathbf{2 8}$, it is found that the substituent always possesses the more thermodynamically stable configuration. Since there are no orbital symmetry demands involved in this ring closure, it is not surprising to have the step thermodynamically controlled.

With this mechanistic concept for the formation of a bicyclo[3.1.0]hex-2. ene in mind, it is of interest to re-examine the photochemistry of trans,cis,ciscyclonona-1,3,5-triene (14). It will be recalled that no bicyclo[3.1.0] hexene derivative was formed upon irradiation of the triene, only the products 15a and 15b. If the initial step in the formation of the bicyclo[3.1.0]hexene be the conrotatory formation of the cyclopropane ring, then it is readily seen from molecular models that the resulting structure 33 with its trans arrangemen of the carbon bonds on the cyclopropane makes ring closure to a five membered ring highly improbable. 

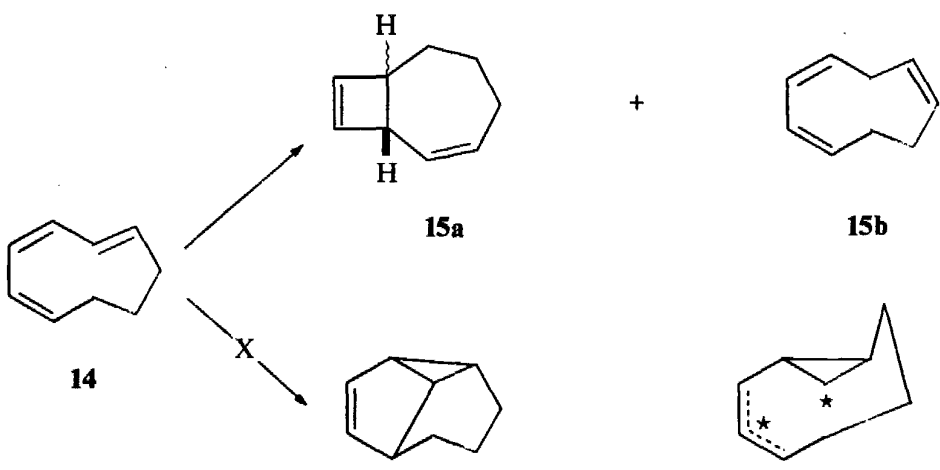

33

The foregoing discussion of the photochemistry of a 1,3-cyclohexadienetype system has been directed towards the ring opening process to yield a 1,3,5-hexatriene system. Such a process represents only one of two orbital symmetry allowed processes for this chromophore, the other being an electrocyclic disrotatory closure to a bicyclo[2.2.0] hex-2-ene. The first example
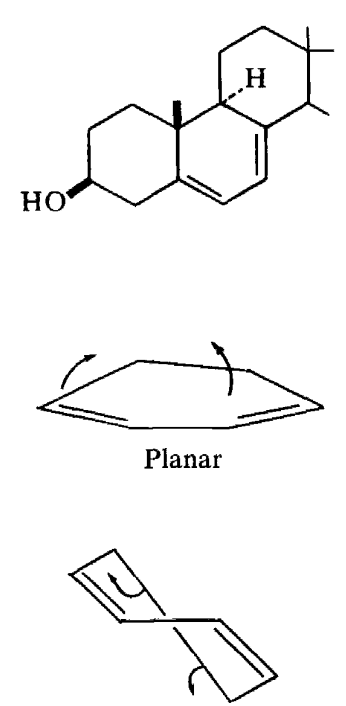

Half-chair
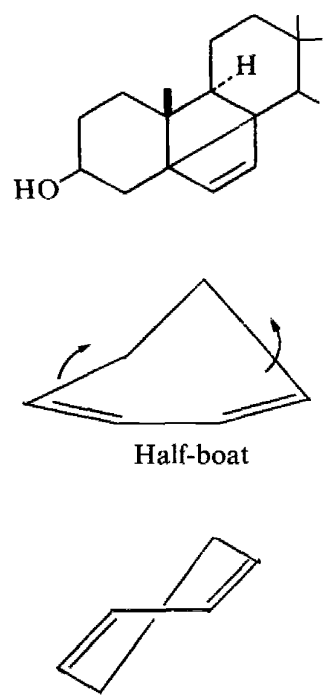

Half-chair

of this type of reaction was reported with the 9,10-syn isomer of pro-vitamin $\mathrm{D}_{2}$, i.e. pyrocalciferol ${ }^{12}$. In this compound which has changed the stereochemistry of only one asymmetric centre, the photoreaction is highly selective. Such a specificity for a disrotatory ring closure rather than a conrotatory ring opening is suggestive of a process which is governed by the 'accordant rule' ${ }^{13}$. Examination of a molecular model of pyrocalciferol shows the cyclohexadiene ring system to be flat or slightly in a half-boat conforma- 
tion. In such a conformation the more favoured accordant motion is disrotatory and such a movement of the carbon atoms of the ring system leads to a bicyclo[2.2.0] hex-2-ene structure. In a ring system where the half-chair conformation is preferred, such as pro-vitamin $\mathrm{D}_{2}$, the preferred accordant motion is conrotatory and leads to a ring opened triene.

The generality of this type of conformational analysis of photochemical processes was clearly demonstrated by the reactions of laevopimaric acid ${ }^{14}$ and palustric acid ${ }^{2}$. With palustric acid the lower energy conformations are of a half-chair type and the expected accordant, conrotatory ring opening occurred. With laevopimaric acid, however, the placement of one of the diene double bonds exocyclic had a dramatic effect in this type of rigid

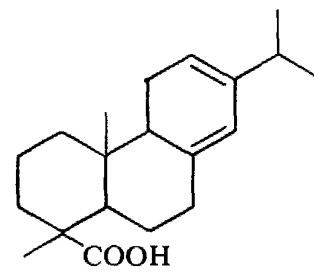

Laevopimaric acid (planar)

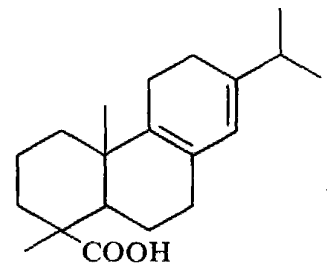

Palustric acid (half-chair)
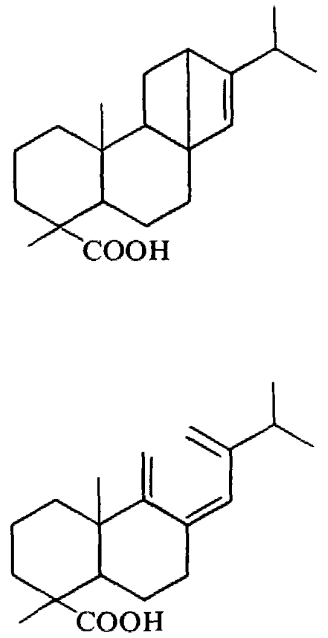

tricyclic A,B-trans fused ring system and irradiation led only to the ring closure product. X-ray studies ${ }^{15}$ of a laevopimaric acid have confirmed early postulates, based upon o.r.d. ${ }^{16}$ and n.m.r. spectra ${ }^{16,17}$, and upon surface film measurements ${ }^{18}$, that the diene ring system existed in the 'folded' conformation and the dihedral angle of the diene system was shown to be $9^{\circ}-11^{\circ}$. From such a conformation the chromophore favours a disrotatory process. This unexpected conformation of a potential extended ring system has been attributed to purely steric effects associated with the methylene and methyl groups attached to C-10, i.e. the '4-4 dimethyl effect'

These suggestions that peripheral substituents have an effect on the conformational equilibrium which, in turn, controls the photochemistry of the 1,3-cyclohexadiene system have been evaluated. A series of simple hexalins have been prepared and their photochemistry evaluated (see Chart VI). The study showed that peripheral substituents had a large effect on the photochemistry of the compound. As the substitution pattern changed it was possible to have selectivity for ring closure or ring opening and, in addition, little preference for either process. It was found that with the substitution 


\section{Chart VI}<smiles>CC1(C)CCC(C)(C)C(C(=O)O)(C(=O)OCc2ccccc2)C2(C)C3CC=CC=C3CCCC12</smiles><smiles>CC1(C)CCCC2CC=CC=C21</smiles><smiles>C1=CCC2CCCCC2=C1</smiles><smiles>CC1(C)CCC2CC=CC=C2C1</smiles><smiles>C1=CCC2CCCC2=C1</smiles><smiles>CC1(C)CCC2=CC=CCC2C1</smiles><smiles>C1=CCC2CCCCCC2=C1</smiles><smiles>CC1CCCC2=CC=CCC21</smiles><smiles>CC1CCC2C(=CC=CC2(C)C)C1</smiles><smiles>C1=CCC2CCCCC2=C1</smiles>

pattern related to a laevopimaric acid, the gem-dimethyl grouping controlled the photoreaction and only ring closed product was formed. The finding that compounds lacking this grouping also yielded ring closed material as well as the ring opened triene suggested that the geminal substitution only accentuated the ring closure and it was not fully responsible for it.

Substituent effects have been found in many photochemical reactions but this present finding of substituents not on the atoms involved in the photo-

Chart VII

$<$

$h v$<smiles>C1=CCC2CCCCC2=C1</smiles>

$\stackrel{h v}{=}$<smiles>C=C/C=C\C1=CCCCC1</smiles><smiles>C=C</smiles><smiles>C=C/C=C\C1=CCCCC1</smiles><smiles>C=[13CH]</smiles>
hv<smiles>C=CC1C=C2CCCCC21</smiles><smiles>C=C1CC1</smiles><smiles>C=CC=CC1=CCCCC1</smiles><smiles>C1=C2CCCCC2C2CC12</smiles> 
chemical process is rare. One plausible explanation of such an effect could be that the peripheral grouping affected the ground state conformational equilibria of the various dienes. As shown in Chart VII, it is possible that in all compounds the primary photoprocess is ring opening of the diene to the triene and subsequent reactions depend upon the efficiency of the various reversible photoreactions. Using 2,4-hexalin as an example, the first formed photoproduct would be the acyclic triene. If the triene remained in an s-cis,s-cis conformation, it is known that ring closure of trienes in this conformation to 1,3-cyclohexadienes is an efficient process; a photoequilibrium between diene and triene results. Such a reversible process keeps the diene present in the reaction mixture and this diene in turn, may be irreversibly transformed to a bicyclo[2.2.0] hexene. As the substituents on the atoms of the triene system are changed, it is possible for conformational and stereochemical changes to be favoured and the resulting new configuration may have different spectral properties as well as different photoreactions. As has been discussed previously, a change to an s-trans,s-cis conformation can lead to a favoured formation of a bicyclo[3.1.0]hexene and a cis-trans isomerization of the central double bond can lead to a favoured formation of a vinylcyclobutene.

The photochemistry of bicyclo[4.3.0]nona-2,4-diene clearly illustrates the importance of the reversibility of the diene-triene interconversion ${ }^{8}$. As shown in Chart VIII, when the diene was irradiated with a mercury

\section{Chart VIII}
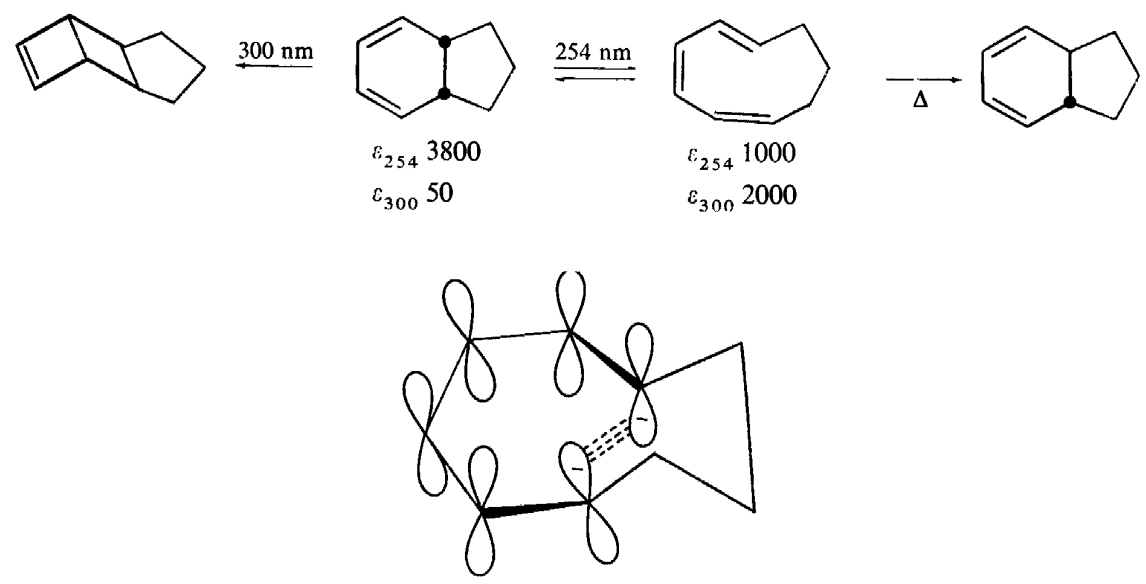

resonance lamp ( $>90 \%$ at $254 \mathrm{~nm}$ ) a photoequilibrium of the diene and triene resulted, little bicyclo[2.2.0] hexene was detected. When only light of a wavelength greater than $300 \mathrm{~nm}$ was used, the sole product of an extended irradiation was the bicyclo[2.2.0]hexene derivatives. The efficient closure of the triene system at the longer wavelength is due to the conformation of the triene which keeps the terminal ends of the triene chromophore in a configuration which favours ring closure to a 1,3-cyclohexadiene structure and to the intensity of the absorption band at $300 \mathrm{~nm}$. 
Although the foregoing results illustrate that the concept of reversibility of the diene-triene reaction can account for the ultimate formation of a bicyclo[2.2.0] hexene derivative, it is evident that other factors must play a role in the overall process. For example, as mentioned earlier and shown in Chart IX, a photoequilibrium is known to exist between palustric acid and its ring opened triene but no bicyclo[2.2.0]hexene is formed. Definitive

Chart IX
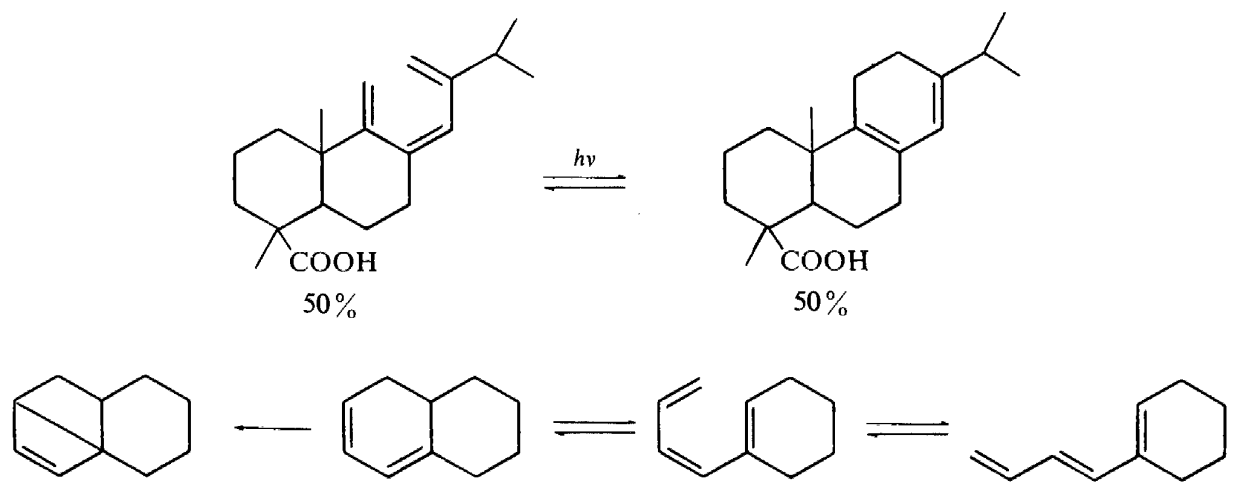

studies in the 2,4-hexalin system further support the concept that features other than the reversibility of the diene-triene system are important. This cyclic diene upon irradiation is known to yield both the triene and the bicyclo[2.2.0]hexene derivative. The triene, itself, was prepared and when it was irradiated no bicyclo[2.2.0] hexene was formed.

Another ground state effect which might play a role in the complex series of photochemical reactions is the conformational equilibrium of the starting 1,3-cyclohexadiene. The geometric arrangements of the atoms of the chromophore are known to have an effect upon the efficiency of the internal conversion from the excited state. In the series of hexalins studied, it has been found that the quantum yields for the disappearance of the dienes are approximately the same for all the compounds studied. This result shows that the different reaction routes followed by the various compounds do not depend upon a selective internal conversion.

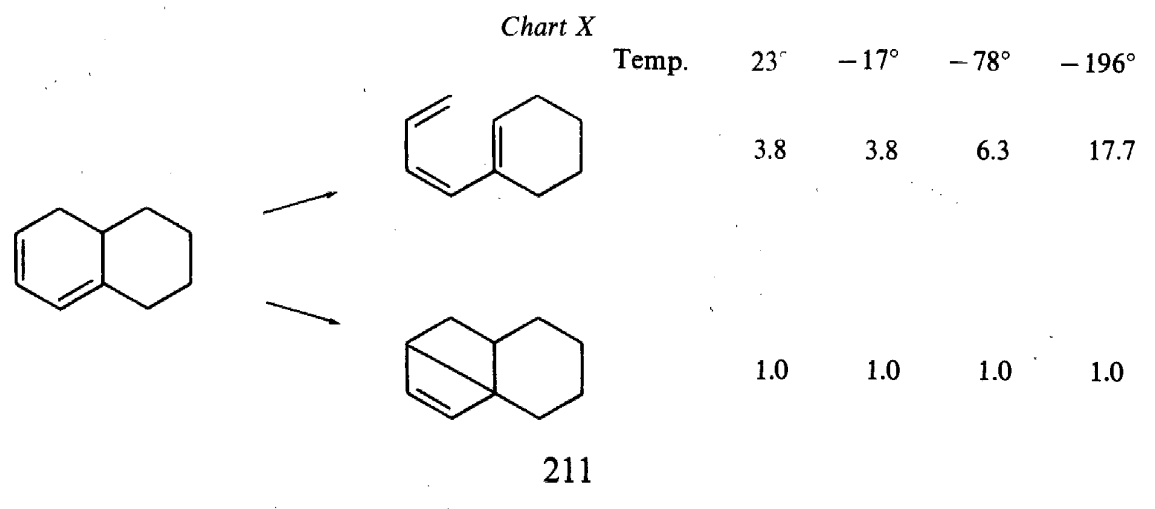


The role of the conformational equilibrium of the starting diene in the overall photochemical process was evaluated by a study of the temperature dependence of the photoreaction. The results are summarized in Chart $X$ and the results show that as the temperature of the reaction was lowered, increased amounts of open chain triene were formed. Such results suggest ground state conformational control of the photochemical process since the concentration of the half-chair conformation should increase as the temperature is lowered and such a conformation should lead to the accordant conrotatory ring opening to the triene.

Before final evaluation of these temperature dependence results, it is essential to show that it is a ground state effect and not an excited state effect. For example, it is possible that from the vibrationally relaxed excited state $\mathrm{S}_{1}$ there are energy barriers to the reactions under consideration. As shown in Chart $X I$, if such be the case the temperature effect would indicate a lower

\section{Chart XI}

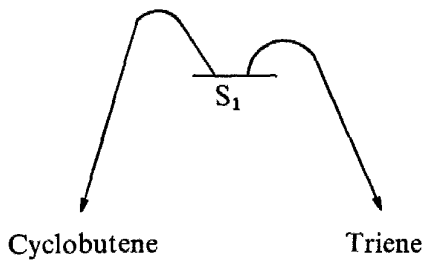

Temperature

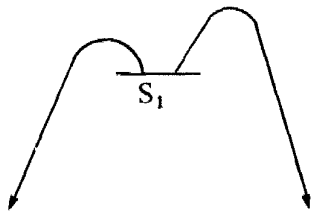

Cyclobutene

Triene

Wavelength

barrier for triene formation than for bicyclo[2.2.0]hexene formation. When the wavelength dependence of the reaction was studied it was found that as lesser energy was put into the molecule, more of the bicyclo[2.2.0]hexene was formed. This result would suggest that the energy barrier to the bicyclo[2.2.0] hexene formation was similar or lower than that to the triene, a conclusion opposite to that suggested by the temperature dependence studies. The result is in line with a ground state conformational control since at the longer wavelength there would be selective excitation of the planar conformation. Consideration of these two studies suggests that the temperature effect observed is a ground state effect.

The two-dimensional energy diagram shown in Chart $X I I$ can serve as a basis for the further understanding of the ground state conformational control of the photochemistry of the 1,3-cyclohexadiene chromophoric system, a system which can be transformed into two different types of compounds depending upon which orbital symmetry allowed mode, conrotatory or disrotatory, is followed. It is known that the ground state energy of the cyclic system goes up as the dihedral angle of the diene chromophore approaches zero. The excited state most likely has its minimum energy at a different 


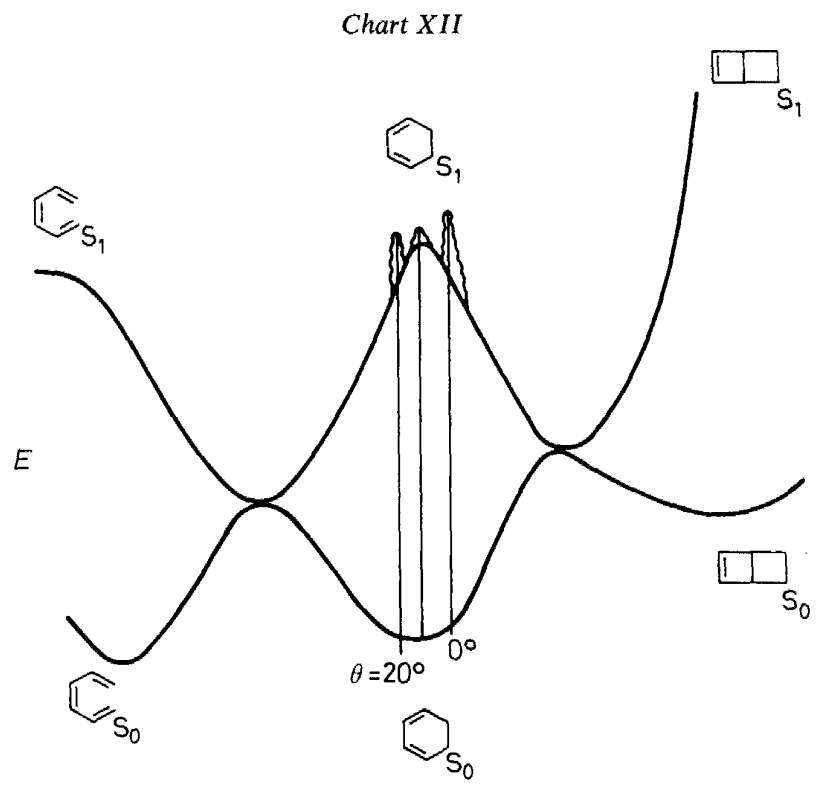

Reaction coordinate

geometry from that of the ground state but, as illustrated, all that is important to the present discussion is that the $\mathrm{S}_{1}-\mathrm{S}_{0}$ energy difference shall increase as the skew angle changes from $0^{\circ}$ to $20^{\circ}$.

The energy surface of the excited state of the diene is only a portion of the general energy surface for all possible arrangements of the $\mathrm{C}_{6} \mathrm{H}_{8}$ moiety. On this overall energy surface must be regions related to the bicyclo[2.2.0]hexene and to the acyclic hexatriene and these areas must be connected with that of the 1,3-cyclohexadiene. As discussed earlier, the planar arrangement of the chromophore leads to a preferential ring closure to the bicyclo[2.2.0]hexene system and such a finding is in agreement with theoretical calculation $\mathrm{s}^{19}$. It follows that the portion of the energy surface connecting the cyclohexadiene and the bicyclo[2.2.0]hexene should be in the $0^{\circ}$ skew region. Furthermore, it is known ${ }^{20}$ that it is the ground state $S_{0}$ of the bicyclo[2.2.0] hexene which is connected with the $S_{1}$ surface of the diene. In a similar manner the connection of the energy surface of the diene and the hexatriene should be in the area of the $20^{\circ}$ skew region. In this case, both the $S_{1}$ and $S_{0}$ states of the triene can be connected with the diene $S_{1}$ energy surface. In a three-dimensional projection, the $S_{1}$ surface would have many valleys corresponding to the low energy form of the various compounds in this series and the energy barriers between the energy minima would differ. Thus, if a molecule arrive in the excited state with a geometry which placed it on the side of a barrier, the molecule would cascade down to the energy minimum. If the molecule arrived in the excited state with an energy which placed it at a position where as it vibrationally relaxed it had a choice of routes to follow, the molecule would distribute itself among the various pathways available to it on the energy surface. 
In any one excited state geometry there is no requirement that all possible reaction pathways be available to the excited molecule.

Excitation can occur from any geometrical arrangement if the proper wavelength of light is employed. Following the Franck-Condon principle, the molecule must have the same geometry when it arrives in the excited state as it had when it left the ground state. For example, if the molecule had a skew angle near $0^{\circ}$ in the ground state, it will initially have the same geometry in the excited state. In such a case, the molecule may already be trapped in an energy well common to both the bicyclo[2.2.0] hexene and the cyclic diene and due to the irreversible formation of the former type of structure it will be the reaction product. In a similar manner, a molecule with a fixed skew angle near $20^{\circ}$ may give only ring opened triene. With a molecule having intermediate skew angles, a mixture of the two products could be obtained. The exact composition would depend upon the position of overlap of the various sections of the energy surface. Thus, the geometry of the 1,3-cyclohexadiene at the time of excitation can control the photochemical process.

At this stage of the study of the photochemistry of the 1,3-cyclohexadiene chromophore many details of the mechanism of the processes and the effect of the ground state geometry on these processes are known. What is lacking is a diagnostic tool which will give more information about the conformational equilibrium. Until such information is available, predictions with regard to the photochemistry of a new compound must be based solely upon results obtained with a closely related compound except for molecules which have a frozen conformation.

\section{ACKNOWLEDGEMENT}

This work was supported in part by the National Institute of Arthritis and Metabolic Diseases, US Public Health Service, Grant No. AM-00709.

\section{REFERENCES}

${ }^{1}$ G. M. Sanders, J. Pot and E. Havinga, Fortschr. Chem. Org. Naturstoffen, Vol. 29, p 131. Springer: New York (1969).

2 W. G. Dauben and R. M. Coates, J. Org. Chem. 29, 2761 (1964).

3 W. G. Dauben, J. Rabinowitz, N. D. Vietmeyer and P. H. Wendschuh, J. Amer. Chem. Soc. 94, 4285 (1972).

${ }^{4}$ W. G. Dauben, P. Baumann and D. Gagnier, in press.

5 W. G. Dauben, I. Bell, T. W. Hutton, G. F. Laws, A. Rheiner Jr and H. Urscheler, J. Amer. Chem. Soc. 80, 4116 (1958);

W. G. Dauben and P. Baumann, Tetrahedron Letters, 565 (1961).

6 a G. R. Evanega, W. Bergmann and J. English, J. Org. Chem. 27, 13 (1962);

${ }^{b}$ H. Prinzbach and E. Druckrey, Tetrahedron Letters, 2959 (1965),

H. Prinzbach, H. Hageman, J. H. Hartenstein and R. Kitzing, Chem. Ber. 98, 2201 (1965);

c K. J. Crowley, Tetrahedron Letters, 2863 (1965); Photochem. and Photobiol. 7, 775 (1968);

${ }^{d}$ R. C. Cookson and D. W. Jones, J. Chem. Soc. 1881 (1965);

B J. Meinwald, A. Eckell and K. L. Erickson, J. Amer. Chem. Soc. 87, 3532 (1965);

J. Meinwald and P. H. Mazzocchi, J. Amer. Chem. Soc. 88, 2850 (1966);

J. Meinwald and P. H. Mazzocchi, J. Amer. Chem. Soc. 89, 1755 (1967);

${ }^{f}$ R. C. Cookson, S. M. De B. Costa and J. Hudec, Chem. Commun. 1272 (1969);

\& A. Padwa and S. Clough, Chem. Commun. 417 (1971);

${ }^{h}$ H. Heimgartner, L. Ulrich, H. J. Hansen and H. Schmid, Helv. Chim. Acta, 54, 2313 (1971);

$i$ D. A. Seeley, J. Amer. Chem. Soc. 94, 4378 (1972).

7 O. L. Chapman, G. W. Borden, R. W. King and B. Winkler, J. Amer. Chem. Soc. 86, 2660 (1964);

W. R. Roth and B. Peltzer, Angew. Chem. 76, 378 (1964); 


\section{PHOTOCHEMISTRY OF CONJUGATED DIENES AND TRIENES}

J. Zirner and S. Winstein, Proc. Chem. Soc. 235 (1964).

8 W. G. Dauben and M. S. Kellogg, J. Amer. Chem. Soc. 93, 3805 (1971).

9 R. W. Woodward and R. Hoffmann, The Conservation of Orbital Symmetry, p 79. Academic Press: New York (1970).

10 W. G. Dauben and J. S. Ritscher, J. Amer. Chem. Soc. 92, 2925 (1970).

${ }^{11}$ R. S. H. Liu and Y. Butt, J. Amer. Chem. Soc. 93, 1532 (1971).

12 W. G. Dauben and G. J. Fonken, J. Amer. Chem. Soc. 81, 4060 (1959).

13 J. E. Baldwin and S. M. Krueger, J. Amer. Chem. Soc. 91, 6444 (1969);

C. W. Spangler and R. P. Hennis, Chem. Commun. 24 (1972).

14 W. G. Dauben and R. M. Coates, J. Amer. Chem. Soc. 86, 2490 (1964).

${ }_{15}$ U. Weiss, W. B. Whalley and I. L. Karle, J. Chem. Soc., Chem. Commun. 16 (1972).

16 A. W. Burgstahler, H. Ziffer und U. Weiss, J. Amer. Chem. Soc. 83, 4660 (1971);

U. Weiss, H. Ziffer and E. Charney, Chem. \& Ind. (London), 1286 (1962);

U. Weiss, H. Ziffer and E. Charney, Tetrahedron, 21, 3105 (1965).

17 J. L. W. Chien, J. Amer. Chem. Soc. 82, 4762 (1960); A. W. Burgstahler, J. N. Mark and D. F. Zinkel, J. Org. Chem. 34, 1550 (1969).

${ }_{18}$ U. Weiss and N. L. Gershfeld, Experientia, 18, 355 (1962).

19 W. Th. A. M. van der Lugt and L. J. Oosterhoff, J. Amer. Chem. Soc. 91,6042 (1969).

20 W. G. Dauben and W. T. Wipke, Pure. Appl. Chem. 9, 539 (1964). 